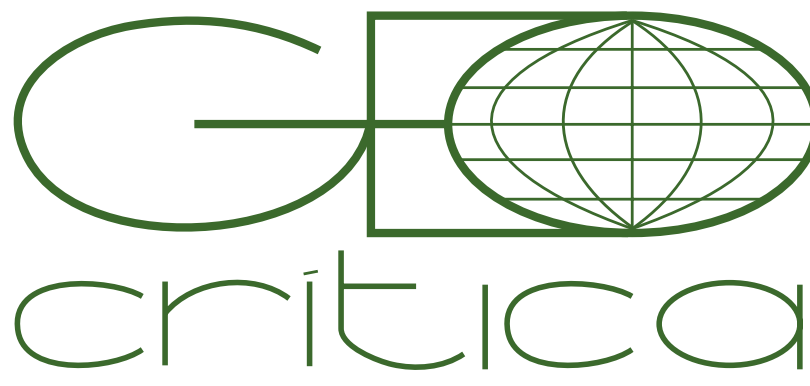

\section{Scripta Nova}

Revista Electrónica de Geografía y Ciencias Sociales Universitat de Barcelona

\title{
DIFERENCIAS TERRITORIALES, SOSTENIBILIDAD Y COMUNES INMATERIALES EN LAS COSTAS AUSTRALES CHILENAS
}

\author{
Alfredo Macías Vázquez \\ Departamento de Economía y Estadística \\ Universidad de León \\ amacv@unileon.es \\ Gonzalo Saavedra Gallo \\ Instituto de Estudios Antropológicos \\ Universidad Austral de Chile \\ gonzalo.saavedra@uach.cl
}

Este trabajo ha

sido posible en el marco de los proyectos Fondecyt Regular no 1171309 "Condicionamientos socio-ambientales y económico-culturales de la producción y la intermediación en el espacio pesqueroartesanal chileno. Una investigación antropológica sobre los límites de la transformación social" y Fondecyt

de Iniciación

no 11110542:

"Escenarios del desarrollo pesqueroartesanal en el contexto de la expansión salmonera. Antropología de las dinámicas económico-culturales en las costas del suraustral chileno".
Recibido: 30 octubre 2018; Devuelto para correcciones: 27 agosto 2019; Aceptado: 6 marzo 2020

\section{Diferencias territoriales, sostenibilidad y comunes inmateriales en las} costas australes chilenas (Resumen)

Analizamos cómo la gestión de los recursos inmateriales comunes afecta el desarrollo sostenible de las zonas costeras. A partir de una investigación etnográfica, nos concentramos en el estudio de dos producciones marinas, el erizo y el chorito, en cuatro localidades representativas del espacio pesquero-artesanal del sur de Chile. Observamos dos pautas a través de las cuales las élites globales y/o locales cooptan el valor simbólico generado por las comunidades locales con un resultado común: la sobreexplotación de los recursos naturales, la degradación ambiental, el deterioro de las condiciones socioeconómicas de la población y un desempoderamiento de las comunidades en beneficio de las élites. Cuestionamos la retórica neoliberal sobre las ventajas competitivas de las diferencias territoriales en el marco de la globalización y concluimos que estos territorios sufren la depredación de sus recursos comunes (materiales e inmateriales) como resultado de las estrategias rentistas de las élites (burguesías locales y empresas transnacionales).

Palabras clave: Territorio, sostenibilidad, comunes, renta, Chile.

\section{Territorial differences, sustainability and immaterial commons in the chi- lean southern coasts (abstract)}

We analyze how the management of common immaterial resources affects the sustainable development of coastal areas. Based on an ethnographic research, we focus on the study of two marine productions, the sea urchin and the mussel, in four representative localities of the fishing-artisanal area of southern Chile. We observe two patterns through which global and/or local elites co-opt the symbolic value generated by local communities that lead to a common result: overexploitation of natural resources, environmental degradation, deterioration of the socioeconomic conditions of the population, and an disempowerment of communities for the benefit of elites. We conclude that the territories suffer the depredation of their common resources (material and immaterial) as a result of the rentier strategies of the elites (local bourgeoisie and transnational corporations).

Key words: Territory, sustainability, common, rent, Chile. 
Frecuentemente, la inserción de las comunidades locales en los mercados globales va acompañada de un proceso de sobreexplotación, degradación y agotamiento de los recursos materiales comunes que durante siglos han permitido a estos grupos sociales reproducir sus formas de vida. En este trabajo, nos interrogamos sobre la posibilidad de explicar las dinámicas ambientales de las comunidades locales, especializadas en producciones tradicionales, en términos de los procesos de valorización que caracterizan una economía post-industrial, donde los procesos de diferenciación en la producción permiten la acumulación de valor inmaterial o simbólico que potencialmente mejora la rentabilidad en la explotación de los recursos materiales ${ }^{1}$. Concretamente, nos preguntamos en qué medida dichas comunidades pueden replantear sus futuras estrategias de desarrollo, haciéndolas más sostenibles, en una economía post-industrial donde los procesos de generación de valor dependen en mayor medida de la gestión de los recursos inmateriales comunes. Para ello, resulta fundamental replantear el debate teórico sobre la gobernanza de los recursos comunes, modificando sustancialmente las preguntas centrales que han definido su contenido ${ }^{2}$. En lugar de preguntarnos sobre qué tipo de gobernanza es necesaria para evitar el agotamiento de los recursos materiales escasos ${ }^{3}$, creemos que resultaría más interesante preguntarse sobre los procesos de acción colectiva que permiten desarrollar los recursos comunes inmateriales que se generan en los procesos de explotación de los recursos materiales, como una manera de garantizar la sostenibilidad de estos últimos a largo plazo. Este cambio obedece a las nuevas dinámicas de valorización que se desencadenan con la irrupción de una economía post-industrial ${ }^{4}$, donde la generación de valor (entendido como la diferencia entre el precio final y el coste de producción) y las disputas en torno a su apropiación se encuentra estrechamente vinculada con la gestión de los recursos inmateriales comunes disponibles en cada territorio.

En las últimas décadas, se ha prestado poca atención a la acción colectiva de comunidades rurales locales en relación a la gestión de sus recursos inmateriales comunes $^{5}$. No obstante, tan importante como la gestión local de las producciones materiales son los ensamblajes globales donde se desarrollan los conflictos y las negociaciones en torno a la co-optación, la captura y la expropiación de dichos recursos inmateriales comunes. En consecuencia, es fundamental comprender la relación entre valor y poder que deriva de la interacción entre la producción de estos recursos inmateriales comunes, como resultado de las prácticas y conocimientos desarrollados por las comunidades locales, y los flujos globales de valor que se generan en una economía post-industrial.

La problemática que enfrenta la acción colectiva de los recursos comunes inmateriales posee una naturaleza diferente a la que subyace en la gestión de los re-

1 Sierra Caballero, 2019; Hardt y Negri, 2009; De Angelis, 2007; Thrift, 2005.

2 Macías Vázquez y Alonso González, 2016.

3 Ostrom, 1990.

4 Rullani, 2004.

5 Harvey, 2002; Lockie, 2001; Pratt, 2007; Zepeda 2014. 
cursos materiales comunes ${ }^{6}$. En realidad, el carácter crecientemente rentista de las elites empresariales lleva a la apropiación externa del valor inmaterial producido por estas comunidades, que no obstante continúan enfocando su atención colectiva en cuestiones prácticas de producción material. La valorización de los productos materiales se origina crecientemente en procesos de producción simbólica, que da lugar a una apropiación de dicho valor generado mediante la forma de renta por parte de actores extraterritoriales o élites locales. Esta dinámica económica lleva, en última instancia, al desempoderamiento de estas comunidades, tanto frente a élites locales como a entidades multinacionales, obligando a las primeras a intensificar la explotación de los recursos materiales comunes para mantener sus niveles previos de ingreso.

El objetivo de este trabajo es analizar cómo afecta la gestión de los recursos inmateriales territoriales en la capacidad de apropiación de valor por parte de las comunidades locales en una economía postindustrial. En este sentido, nos preguntamos de qué modos se insertan los colectivos del place-según el concepto propuesto por Escobar - en los ensamblajes globales donde se desarrollan los mencionados procesos de apropiación, los modos por los que se producen ciertas representaciones culturales, y cómo estas favorecen o no la explotación o captura de los recursos inmateriales locales por actores extra-territoriales o elites locales. Frente a una retórica neoliberal que considera el proceso de globalización una oportunidad para poner en valor las diferencias de los territorios ${ }^{8}$, que considera el "lugar" como una mercancía que se reformula permanentemente para atender a los deseos de los consumidores, en este trabajo analizamos cómo la gestión de los recursos comunes inmateriales es un ámbito sujeto a intensos conflictos sociales, con efectos significativos sobre la evolución de los recursos materiales de las comunidades.

El trabajo se divide en tres apartados. En primer lugar, analizamos la relevancia que la gobernanza de los recursos inmateriales comunes tiene en los procesos de generación de valor en una economía postindustrial y en la sostenibilidad ambiental de los territorios. En segundo lugar, analizamos la gestión de los comunes inmateriales en cuatro escenarios representativos del espacio pesquero-artesanal en Chile, en particular Melinka (región de Aysén); Quellón y Calbuco (región de los Lagos); y Los Molinos (en Valdivia, región de Los Ríos). Concretamente, nos concentramos en el estudio de dos producciones marinas relevantes en el sur del país: el erizo (loxechinus albus) y el chorito (mytilus chilensis). Por último, se discuten los resultados de la investigación y se plantean unas conclusiones finales.

Los estudios de caso corresponden a dos proyectos de investigación del Fondo Nacional de Desarrollo Científico y Tecnológico de Chile (Fondecyt), el primero desarrollado entre 2011 y 2014; y el segundo en plena ejecución (2017-2020). En este marco, se han empleado metodologías combinadas de investigación, tanto cualita-

6 Hardt y Negri, 2009.

7 Escobar, 2008.

8 Ray, 1998; Cruickshank, 2009. 
tivas como cuantitativas, incluyendo trabajos de campo etnográfico, con aplicación de entrevistas semiestructuradas, grupos de discusión con actores locales (principalmente pescadores artesanales sindicalizados, incluyendo productores bordemarinos en Calbuco) y una encuesta de escala tipo Likert a 300 pescadores (hombres y mujeres). Esta encuesta, realizada en 2017 y 2018, es referencial y su foco estuvo en la intermediación, la pesca artesanal y en el mar. Aquí se presentan los resultados referidos a intermediación en tres localidades representativas de la pesca artesanal en Chile: Calbuco, Los Molinos (Valdivia) y Los Vilos (no incluida como caso etnográfico en este análisis. La consideración "tipo Likert" estriba en el diseño muestral (no estadístico) que hemos utilizado en esta investigación, decisión derivada del tipo de población estudiada (demográficamente baja y circunscrita a la pesca artesanal) y sobre todo a la orientación cualitativa de nuestro enfoque. En total se entrevistó a 30 personas durante la primera etapa, y en lo que va de la segunda a 40 (cuadro 1). Las entrevistas a intermediarios corresponden a la segunda etapa de la investigación, específicamente se entrevistó a 3 intermediarios en Calbuco y 2 en Los Molinos; asimismo se han realizado 7 grupos de discusión para indagar los impactos del mercado en los sistemas bentónicos de base artesanal y asimismo en la mitilicultura. Las instancias fueron realizadas en Melinka (2012 y 2013), Quellón (2013); Calbuco (2012 y 2017); Los Molinos (2017 y 2018). El diseño muestral para las entrevistas y las encuestas fue de tipo estructural no probabilístico'. En el caso del grupo de discusión se optó por equilibrar la participación entre hombres y mujeres (vinculados a la extracción y comercialización de productos bordemarinos y marinos), estableciendo como rango entre 7 y 12 participantes.

Cuadro 1: Entrevistas semiestructuradas

\begin{tabular}{lcc} 
Localidad & Mujeres & Hombres \\
\hline Los Molinos & 6 & 11 \\
Calbuco & 7 & 14 \\
Quellón & 6 & 8 \\
Melinka & 8 & 10 \\
\hline Total & $\mathbf{2 7}$ & $\mathbf{4 3}$ \\
\hline
\end{tabular}

Fuente: elaboración propia

El desarrollo metodológico del proceso etnográfico se ha desarrollado en 3 etapas: Una etapa prospectiva en donde se plasmaron registros en formato de cuaderno de campo; una etapa intermedia en donde se realizaron las primeras entrevistas, los grupos de discusión y se aplicaron las encuestas tipo Likert; finalmente, una etapa de consolidación investigativa en donde se han realizado la mayor parte de las entrevistas.

9 Canales, 2006; Montañés, 2010. 
El análisis de la información se ha realizado a partir de una sistematización categorial de las entrevistas y las fuentes secundarias narrativas, contrastando testimonios con el propósito de establecer puntos de convergencia y divergencia. Posteriormente los datos obtenidos en las encuestas y cuestionarios han sido triangulados con los citados registros narrativos.

\section{Recursos comunes inmateriales y sostenibilidad: una aproximación teórica}

Se pretende realizar una aproximación alternativa a la problemática de la gobernanza de los recursos comunes, destacando la importancia que la gestión colectiva de los recursos comunes inmateriales tiene en la sostenibilidad ambiental de los territorios y en el empoderamiento de las comunidades locales en la cadena de valor. Para ello, dividimos este apartado en dos secciones. Por un lado, argumentamos por qué es necesario realizar una revisión de la teoría relacionada con la gobernanza de los recursos comunes en el contexto de una economía postindustrial. En este sentido, consideramos la importancia y las características específicas que en dichos procesos de gobernanza tienen los recursos inmateriales. Por otro lado, consideramos por qué es necesario reorientar el análisis de los procesos de acción colectiva en las zonas rurales, demasiado centrados en la gestión de los recursos materiales, para darle más relevancia a los recursos inmateriales comunes. De esta manera, se podrían enfrentar con mayores posibilidades de éxito las estrategias rentistas de las élites, tanto locales como transnacionales.

\section{Los recursos comunes inmateriales y la generación de valor en una economía post-industrial}

Los recursos inmateriales, como las culturas locales o las prácticas productivas específicas de un territorio, entran dentro de la categoría de los llamados "nuevos comunes"10. En este sentido, Hess y Ostrom ${ }^{11}$ se preguntan cómo se puede gobernar una serie de recursos que, como el conocimiento o los activos inmateriales de un territorio, rompen en buena medida con las características que definen los bienes comunes tradicionales. Ambos autores plantean que "los costes de mantener recursos grandes y diversos son mucho mayores que cuando se gobiernan recursos pequeños y relativamente homogéneos", ya que "cuando un recurso es grande y complejo, los usuarios pueden carecer de una comprensión común de la dinámica de los recursos, y con frecuencia tienen intereses sustancialmente diversos"12 . No obstante, Hess y Ostrom no parecen tener en cuenta las diferencias existentes entre ambas clases de bienes comunes. De manera general, defienden que "los problemas potenciales en el uso, la gobernanza y la sostenibilidad de un bien común pueden ser causados por algunas características de los comportamientos humanos que conducen a dilemas

10 Hardt y Negri, 2009; Harvey, 2012

11 Hess y Ostrom, 2007.

12 Ibidem, p 44 
sociales, como la competencia por el uso, el uso gratuito y la sobreexplotación"13 . Para ambos autores, esta vulnerabilidad a los dilemas sociales es la clave para identificar un recurso compartido como bien común. De hecho, llegan a considerar que "las amenazas típicas al conocimiento común son la mercantilización o el cercamiento, la contaminación y la degradación, y la no sostenibilidad"14.

Desde nuestro punto de vista, este tratamiento analítico de los nuevos comunes se aborda bajo dos supuestos muy cuestionables (Macías Vázquez y Alonso González, 2016). Primero, que los recursos -aunque cambiantes- vienen dados y por lo tanto su gestión debe responder fundamentalmente a la pregunta de cómo conservarlos, cómo explotarlos de forma sostenible. Segundo, que la función de la comunidad es exclusivamente reactiva reduciéndose el problema a una cuestión de costes, relacionada con la reformulación recurrente de las reglas de gobernanza comunitaria como consecuencia de un contexto que cambian de forma muy rápida. En estas circunstancias, gestionar los nuevos comunes resultaría más complejo y costoso que gestionar los bienes comunes tradicionales.

Hardt y Negri ${ }^{15}$ distinguen también ambas clases de bienes comunes, pero su enfoque es completamente diferente. Ambos autores consideran que el conocimiento, los activos inmateriales o la propia cultura son también, y con mayor motivo, bienes comunes ya que constituyen un capital necesario para la interacción social y la producción económica ulterior derivada de la misma. En su concepción, los bienes comunes no necesariamente son algo dado, donde el debate se limita a la elección de los mecanismos de gobernanza adecuados para conservar dichos recursos. Lo importante no sería identificar las reglas más apropiadas para enfrentar los dilemas sociales que puedan extinguir los recursos, sino explicar la multitud de procesos complejos que se encuentran implicados en la construcción social de dichos bienes comunes. De hecho, la producción de conocimiento no se vería constreñida por la lógica de la escasez, sino por todos aquellos obstáculos que limitan la capacidad colectiva de compartir e intercambiar socialmente.

En realidad, la producción de los recursos comunes inmateriales es gobernada por leyes que difieren sustancialmente de las que rigen para los restantes procesos de producción. Según Rullani ${ }^{16}$, lo que caracteriza a estos recursos comunes es una cualidad de fondo: cuando se usan no se consumen, sino que encontrándose disponibles para otros usos se multiplican pasando de unos usos a otros. Por un lado, esto ocurre porque la diferencia entre los costes de producción original y de reproducción, de copia, introducen una ruptura entre el pasado y el futuro. Por otro lado, porque estos recursos inmateriales contienen un stock potencialmente infinito de valor útil, correspondiente con todos los posibles usos futuros que, a partir de diferentes interpretaciones simbólicas, pueden darle los diversos colectivos humanos que los consuman. Cuanto más se difundan estos recursos inmateriales, más crece

13 Ibidem, p.5

14 Idem

152009

162004 
su valor. Todo nuevo uso implica una utilidad superior, con un escaso o nulo coste de reproducción. Los conocimientos, la cultura, los activos inmateriales en general, se valorizan al ponerse en común, al difundirse. Rullani formula un modelo para analizar el proceso de generación de valor que tenga en cuenta estas propiedades de los recursos comunes inmateriales. En el mismo, la generación de valor de dichos recursos inmateriales deriva del ensamblaje de tres 'drivers': la capacidad de interpretación por parte de los usuarios de los significados incorporados en la producción material, la cantidad de veces que se propagan y replican estos significados, y la distribución del valor que produce entre los distintos actores que participan en su producción y sostenimiento.

\section{Sostenibilidad, acción colectiva y rentas}

La literatura sobre la gestión colectiva de los bienes comunes se centra habitualmente en cuestiones de conservación de recursos materiales ${ }^{17}$. No obstante, es importante señalar que las formas de organización y producción diferenciada de bienes materiales se asientan en conocimientos comunes inmateriales locales difícilmente replicables: conocimientos implícitos, informales y prácticos, know-hows artesanales, redes de contactos, información, cooperación e intercambio de favores, entre otros. Por otro lado, estas comunidades locales son crecientemente mediadas por procesos reflexivos de consumo y de producción que incorporan valores estéticos exógenos, que son incluidos en los procesos de producción de localidad ${ }^{18}$.

Así, los recursos inmateriales comunes son el resultado de la cristalización histórica de un conjunto de prácticas, relaciones sociales, cualidades físicas e ideas desarrolladas por un grupo humano, que pueden ser percibidas por otros grupos, mercados o estados como 'diferentes', y de esta manera ser objeto de un proceso de valorización. Para Harvey ${ }^{19}$, las marcas de distinción desarrolladas por el capitalismo post-industrial para mantener la explotación monopolística del valor a través de rentas sobre los activos materiales requieren de la participación de dichos recursos comunes inmateriales, que confieren valor añadido en dicho proceso. En esta lógica, por parte de las élites locales y transnacionales se produce una intensificación de la expropiación de los recursos comunes y sus plusvalías mediante la generación de rentas y el endurecimiento de distintas formas de cercamiento inmaterial, como copyrights, patentes y trademarks ${ }^{20}$, con consecuencias negativas sobre la evolución de la sostenibilidad ambiental y social de las comunidades locales. A esto se vincula, no obstante, un discurso justificativo, a menudo apoyado por el Estado, que glorifica el rol del individuo emprendedor que en realidad actúa como algo opuesto, como un 'finder-keeper'21, como un "parásito"22, como un individio que no contribuye a la

17 Van Laerhoven y Ostrom, 2007; Berkes, 2009

18 Comaroff y Comaroff, 2009.

192012

20 Marazzi, 2008; Vercellone, 2008

21 Burczak, 2002.

22 Serres, 2014 
generación de valor sino que se apropia de dicho valor mediante estrategias rentistas. Esto es, no como un auténtico emprendendor, como alguien que ha contribuido a la producción de valor, sino como alguien encargado de apropiarse de un valor previamente existente, generado por las comunidades locales ${ }^{23}$. Ante esta situación, consideramos que la lucha de las comunidades locales por mantener la capacidad de apropiación de valor de sus producciones ya no deriva tanto de la organización de la producción material, sino del control de los recursos comunes inmateriales y de su modulación con la gestión de los recursos materiales.

Pasquinelli señala "la profunda asimetría entre el dominio cultural y la economía material: el valor se acumula en el nivel inmaterial pero las ganancias se obtienen en el material" 24 . Es decir, continuaría generándose un beneficio en la dimensión material de la producción, que depende fundamentalmente de la cantidad de recursos internos disponibles (que normalmente permanecen bajo control de las comunidades, en aquellos casos que no son expropiadas de sus recursos) y del grado de intensidad en su explotación. Sin embargo, las rentas extraíbles de los recursos inmateriales comunes derivan de otras cualidades de carácter intangible, dinámicas en el ámbito difuso de lo inmaterial y que escapan al control de los productores locales. Estos recursos inmateriales comunes interactúan con los patrones de consumo y la percepción de la diferenciación de los productos que se desarrollan en otras culturas, lo que termina alimentando estos procesos de valorización por el lado de la demanda. Paradójicamente, las élites empresariales poseen un mayor conocimiento de los mercados globales y por lo tanto tienen una mayor capacidad de apropiarse de estas rentas inmateriales.

Por ejemplo, a través de técnicas de marketing y de publicidad (o incluso a través de un discurso científico autorizado), dicha élites pueden apropiarse de un recurso previamente generado, como un conocimiento ancestral sobre plantas medicinales. Las comunidades locales han utilizado históricamente estos conocimientos sobre las plantas como un recurso inmaterial común, sin restringir su uso a ninguno de sus miembros, sin establecer un precio, mediante técnicas de extracción que han permitido su explotación sostenible durante siglos. Probablemente, dichas comunidades no se hayan planteado en ningún momento que sus conocimientos sobre plantas medicinales pudiesen ser objeto de deseo entre gentes de otros lugares remotos y, aunque se lo hayan planteado, difícilmente actuarían como las élites empresariales. En realidad, nos encontramos ante una apropiación rentista (en este caso, mediante el establecimiento de patentes farmaceúticas), donde las élites actúan como "finder-keepers" respecto a los recursos cognitivos generados históricamente por las comunidades locales.

En consecuencia, las comunidades ven disminuidas fuertemente sus posibilidades de captar el valor generado por su propia actividad productiva ${ }^{25}$. En general,

23 Hanlon, 2014

24 2008, p. 150-151.

25 Sierra Caballer, 2019; Macías Vázquez y Alonso González, 2015. 
sufren un proceso de desempoderamiento en relación al control de los procesos de generación de valor, que suele derivar en una sobreexplotación insostenible de los recursos naturales para intentar mantener los niveles de ingreso previos. Como resultado, las élites locales suelen salir también perjudicadas, mientras que las élites transnacionales buscan otros territorios alternativos para reproducir su estrategia rentista depredadora.

\section{La gestión de los comunes inmateriales en el espacio pesquero arte- sanal chileno}

A continuación presentamos el análisis de resultados de dos pesquerías que, creemos, son representativas de lo que sucede en el espacio pesquero-artesanal del sur de Chile. Una de estas pesquerías corresponde a recursos íntegramente capturados por las flotas artesanales bentónicas (erizo) y la otra corresponde a productos de acuicultura industrial (chorito). Con el fin de dimensionar el fenómeno de la apropiación del valor inmaterial de las pesquerías, se establecen dos expresiones de la problemática: primero, la recreación simbólica de esos valores, y, segundo, su sustitución. Seguimos en parte la perspectiva crítica sobre la diferencia colonial planteada por Escobar ${ }^{26}$ y Restrepo ${ }^{27}$, autores que, por un lado, advierten sobre la fuerza homogeneizadora de los discursos de la modernidad, pero que, por otro lado, sostienen que cabe repensarla también como un objeto etnográfico, heterogéneo y contradictorio; de tal manera que, bajo este prisma, ambas expresiones reseñadas (recreación y sustitución) implican la obliteración de sus particularidades ideo-materiales y cobran sentido en los mercados de consumo. No obstante, terminan siendo condicionantes del intercambio en los segmentos primarios de la cadena de valor, $y$, consecuentemente, derivan en impactos socio-ecológicos significativos.

\section{El espacio pesquero artesanal chileno y su articulación a los mercados exporta- dores}

Las sociedades pesquero-artesanales se despliegan a lo largo de toda la costa chilena. Sus orígenes se remontan a pueblos prehispánicos que configuraron sistemas de vida basados en la pesca, la caza y la recolección de especies marinas ${ }^{28}$, aunque también bordemarinas ${ }^{29}$. Cabe sostener entonces que, en sus orígenes, los antecedentes remotos de esos pueblos costeros presuponen estrategias adaptativas comunes o similares, geoespacialmente diferenciadas -como las adaptaciones al mar interior en Calbuco, a la costa estuarial en la desembocadura del río Valdivia, o bien a la costa rocosa y abierta del centro-norte del país-, pero siempre inscriptas en particularidades ideo-materiales asociadas a cosmovisiones también diversas. Ahora bien, los procesos de colonización y modernización consagraron transformaciones

28 Llagostera, 1993; Méndez \& Jackson, 2004; Quiroz \& Sánchez, 2004; Reyes et al, 2007.

29 Skewes, Alvarez \& Navarro, 2012. 
sustantivas y significativas en esos modos de vida. Bajo esta premisa, se podría admitir que el devenir poscolonial de los pueblos costeros -en Chile como en toda Latinoamérica- implicó una progresiva articulación a los mercados de distribución y consumo, primero a escala regional y nacional, para posteriormente, como ocurre en la actualidad, consolidarse como economías proveedoras de materias primas de exportación ${ }^{30}$.

De acuerdo con el Registro Pesquero Artesanal (RPA) ${ }^{31}$, para 2016, hay en Chile un total de 98.798 pescadores formalmente inscritos, de los cuales en torno al $25 \%$ son mujeres y casi el $75 \%$ son hombres. Las regiones de mayor concentración -y también de mayor índice de desembarques- son Los Lagos y Biobio, no obstante, como ya se indicó, en toda la costa chilena hay asentamientos pesqueros con notables arraigos en lo que, según observamos, cabe pensar como espacios culturales localizados. Otro factor institucional relevante es el encuadramiento normativo-administrativo de la actividad, con la promulgación de Ley General de Pesca y Acuicultura (LGPA) en los noventa ${ }^{32}$. Los principales dispositivos que regulan la actividad son los regímenes de acceso, el propio RPA, el establecimiento de cuotas limitadas de captura y la regionalización de la pesca artesanal (limitando la movilidad histórica de las flotas hacia otras regiones). También es significativo señalar que, en otra expresión de estas lógicas modernizantes, los pueblos pescadores -tradicionalmente organizados bajo sistemas de parentesco y redes de vecindad-pasaron en forma progresiva a organizarse en cooperativas (años 1960 y 1970), en asociaciones gremiales y sindicatos independientes (años 1980 en adelante), e incluso en microempresas (década de 2000 en adelante). Por último, la condición estructural se refiere aquí al conjunto de relaciones complejas que sitúan a las sociedades litorales en un entramado de intereses y flujos financieros que erosionan su capacidad de auto-reproducción material ${ }^{33}$. La expresión de esta condición es la articulación de la pesca artesanal al mercado, concretamente a los intermediarios (en todas sus variaciones) y a las plantas de proceso.

Los casos analizados se basan en un proceso investigativo que realizamos en dos registros metodológicos complementarios. El primero es documental y considera datos de captura y exportación, también principales mercados de consumo a nivel internacional. El segundo registro es localizado y nos permite construir los casos. Como se ha indicado previamente, se basa en trabajos de campo realizados en tres regiones de importancia pesquero-artesanal en Chile: regiones de Aysén, Los Lagos y Los Ríos. La extensión de los trabajos de campo osciló entre una y tres semanas, siguiendo una secuencia inicial sur-norte. Cada localidad fue visitada en tres (Melinka), cuatro (Quellón), diez (Calbuco) y siete (Los Molinos) ocasiones. Si-

30 Peña-Torres, 1997; Nahuelhual, Saavedra, Blanco, Wesselink, Campos \& Vergara, 2018

31 http://ww2.sernapesca.cl/index.php?option $=$ com_content\&view $=$ article\&id=84\&Itemid=222

32 http://www.subpesca.cl/portal/615/articles-88020_documento.pdf

33 Cunningham and Bostock 2013. 
guiendo el enfoque teórico-metodológico propuesto por Gudeman \& Rivera ${ }^{34}$, nuestro lugar de observación-conversación ha sido principalmente el espacio doméstico de reproducción de la vida material (la casa), ampliando este eje hacia las áreas de extracción (el bordemar) y de intercambio (las ferias). En particular, los grupos de discusión fueron desarrollados en casas de pescadores (3), restoranes de pescadores (2) y en sedes sindicales (2).

La pesquería del erizo se realiza principalmente en el sur-austral, en localidades como Melinka (Aysén) y Quellón (Los Lagos), aunque también es muy significativa en la austral región de Magallanes. Del mismo modo hemos obtenido algunos testimonios en la comuna costera de Valdivia (Los Ríos). El cultivo de choritos o mejillones comprende localidades del mar interior, también en la región de Los Lagos. Los testimonios y las observaciones han sido realizados en las islas Chidhuapi y Puluqui, ambas emplazadas en el archipiélago de Calbuco (Figura 1).

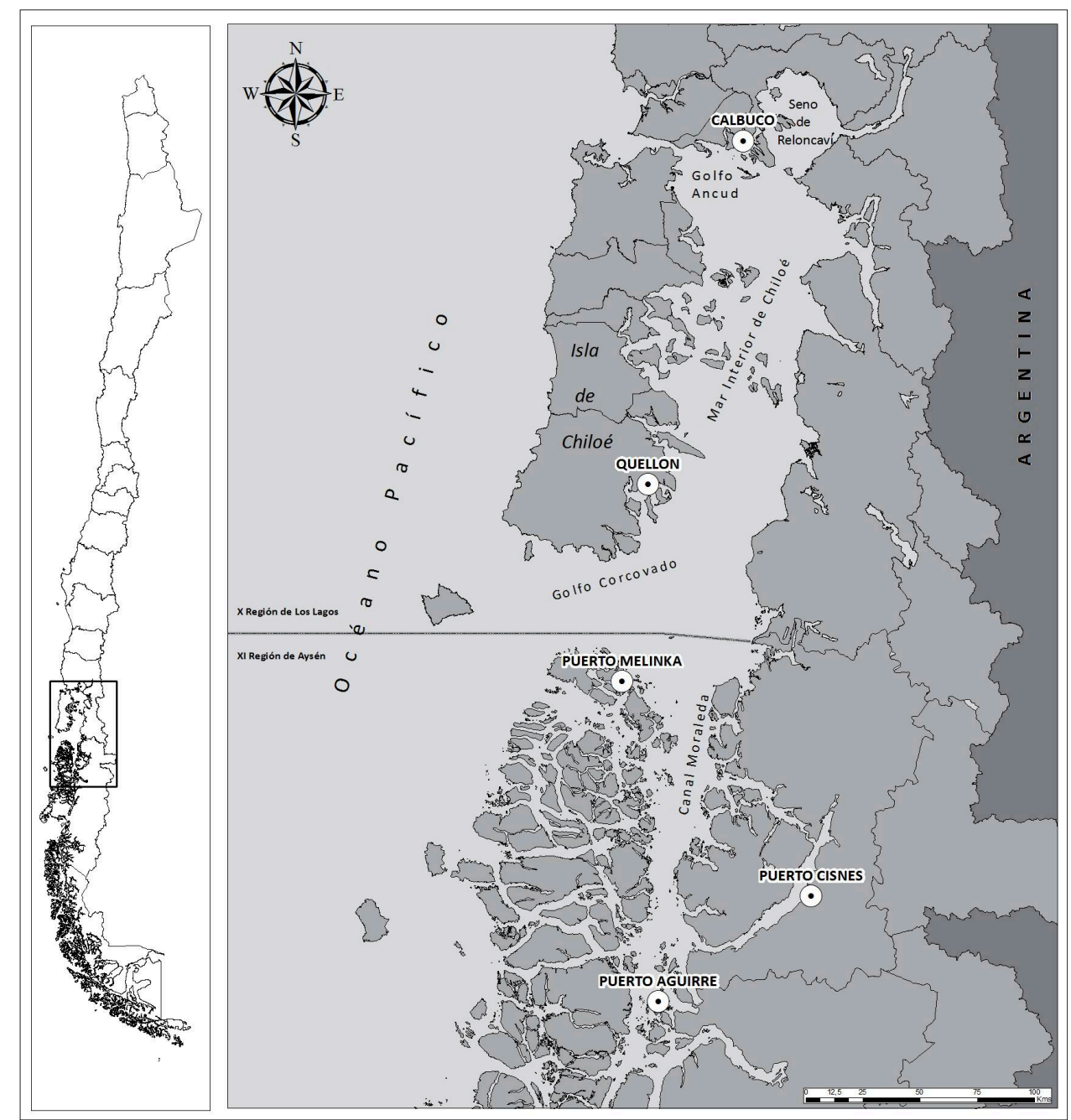

Figura 1. Mapa del Sur Austral de Chile

Fuente: Elaborado por Zamir Bugueño 


\section{La recreación simbólica de los valores inmateriales: la pesquería artesanal del erizo}

El erizo (Loxechinus albus) es una de las principales pesquerías bentónicas en el sur-austral de Chile. Su distribución se extiende desde el norte del Perú hasta las islas del extremo meridional. Su explotación se realiza a través de buceo autónomo (artesanal), entre los 0 y 40 metros de profundidad. El erizo constituyó parte de la dieta que los grupos canoeros desarrollaron en su adaptación a los canales australes durante miles de años ${ }^{35}$. Como sucede con otras pesquerías, su consumo ha sido una constante entre las poblaciones de la costa chilena. De hecho, estadísticas recientes revelan que hasta 1975 su consumo era frecuente a nivel nacional, pero a partir de ese año comienza un auge de exportaciones que derivaría en un aumento exponencial de las capturas. De acuerdo con los datos analizados por Arana (2005), en 1975 se registra un desembarque de 3.000 toneladas, 30.000 en 1985, para alcanzar un promedio de 55.000 en los primeros años de la década de 2000. La mayor parte de los desembarques se registran en localidades insulares emplazadas en el extenso mar interior de Chiloé, Aysén y Magallanes. Podría admitirse que su captura constituye una expresión reciente -desde fines de los años 1990 en adelante- de la secuencia de "fiebres" pesqueras, todas asociadas a la exportación, y más específicamente a la apertura de la economía chilena a los mercados y capitales internacionales ${ }^{36}$. La alta demanda exportadora de erizos implicó un creciente esfuerzo extractivo y una notable dinamización del comercio en las zonas de mayor importancia bentónica, particularmente en comunas como Calbuco y Quellón, en Los Lagos, y Guaitecas, en Aysén, en donde representa, en los últimos quince años, entre el 70\% y el 90\% de todas las capturas bentónicas ${ }^{37}$. No obstante, el notable esfuerzo extractivo ha implicado una fuerte presión sobre los ecosistemas, cuya sobreexplotación ha dado lugar a un progresivo descenso en los desembarques (Figura 2). En 2002, las toneladas desembarcadas eran 60.000 mientras que en 2010 a penas aclanzaban las 30.000. El principal destino de las exportaciones de erizos es Japón, con el 97\% del total. Paralelamente al descenso de los desembarques, se observa un retroceso en las esportaciones, cayendo de 5.020 toneladas en 2002 a 1.800 en $2010^{38}$.

En el ámbito del consumo, advertimos otro nodo central de la problemática. Las principales empresas que exportan el erizo despliegan una estrategia que invisibiliza a los productores locales, instalando en el mercado exportador una marca genérica: "erizo de los mares de la Patagonia chilena" (empresa Agromar), o "sea urchins" como producto destacado "in the northern gate of the chilean Patagonia" (Chile Foods), o "delicias patagónicas" y "delicias australes" para el paté de erizo al coco (Sur Mundo). Sin embargo, las flotas artesanales que capturan erizos pertenecen a localidades muy específicas (Quellón, Melinka, Puerto Aguirre o Puerto Na

35 Cooper, 1946; Orquera y Piana, 2006; Morello et al., 2012

36 Ffrench-Davis, 2002

37 SERNAPESCA 2000-2015

38 IFOP, 2012 


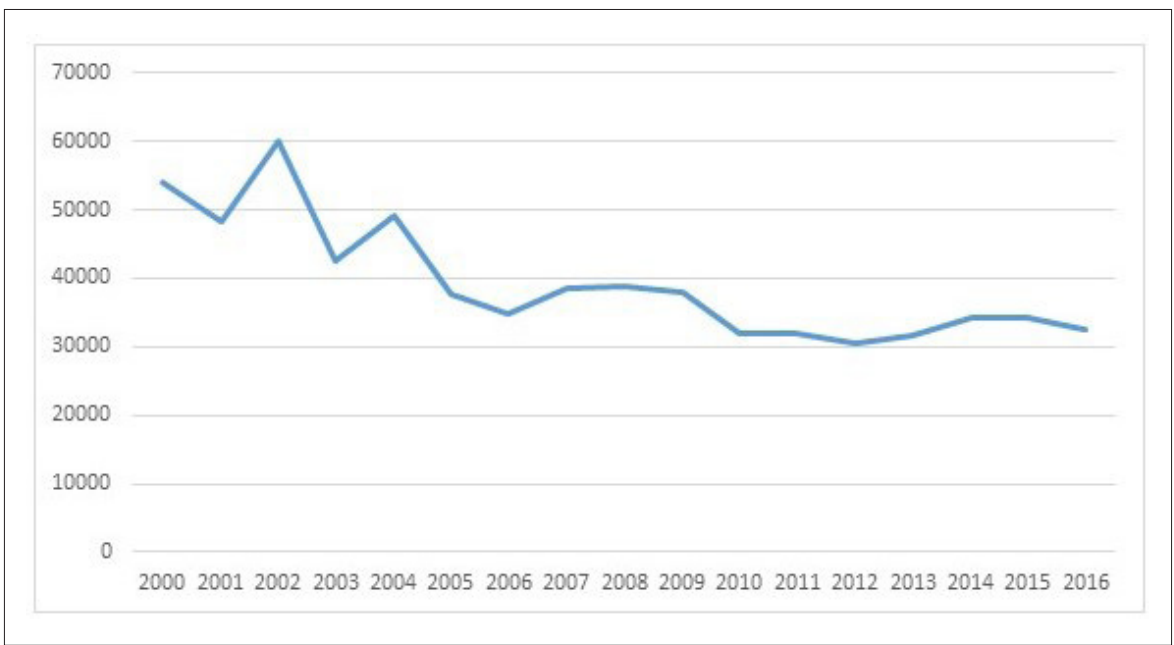

Figura 2. Desembarque artesanal de erizo en Chile (Tn), 2000-2016.

Fuente: Elaboración propia a partir de anuarios estadísticos de SERNAPESCA.

Cuadro 2. Precios en primera venta y precios FOB de exportación del erizo chileno, 2004-2016

\begin{tabular}{lcc}
\hline Año & Precios primera venta US\$/kg. & Precios FOB exportación US\$/Kg. \\
\hline 2004 & 0,6 & 20,5 \\
2005 & 0,6 & 23,3 \\
2006 & 0,5 & 21,9 \\
2007 & 0,5 & 23 \\
2008 & 0,6 & 28,5 \\
2009 & 0,4 & 27,3 \\
2010 & 0,4 & 27,1 \\
2011 & 0,4 & 28 \\
2012 & 0,5 & 32 \\
2013 & 0,6 & 36,1 \\
2014 & 0,9 & 37,5 \\
2015 & 0,6 & 32,6 \\
2016 & 0,8 & 31,4 \\
\hline
\end{tabular}

Fuente: Elaboración propia a partir de anuarios estadísticos de SERNAPESCA y del Banco Central de Chile.

tales), que no corresponden, en ninguna denominación local o nativa, a Patagonia. En realidad, se trata de mares de Chiloé o canales australes de Aysén o Magallanes, o incluso de zonas todavía más específicas en la geografía archipelágica. Además, se añade una absoluta invisibilización de la captura artesanal de erizo a través del buceo. Una práctica que, incluso, fue parte del repertorio de saberes que los extintos 
pueblos canoeros desarrollaron en este territorio litoral. Como veremos más adelante cuando analicemos la intermediación, desde el punto de vista de las comunidades de pesca artesanal, la información respecto de los mercados de destino -incluyendo las nomenclaturas comerciales de los productos- es limitada, pues solo se traduce en impresiones generales o, con mayor recurrencia, en declaraciones de desconocimiento.

De esta invisibilización, deriva la incapacidad de frenar los contrastes entre los precios del erizo en primera venta a intermediarios en los mercados locales y los precios FOB (Free On Board) de exportación. Mientras los precios en primera venta y en el mercado nacional tienden a no variar significativamente, el precio FOB se incrementa año a año (Cuadro 2).

\section{La sustitución deliberada de los valores inmateriales locales: la pesquería del chorito}

El chorito (mytilus chilensis) es un bivalvo filtrador tradicionalmente extraído y consumido en los hogares costeros, y luego, desde principios del siglo XX, entregado (vendido) a las plantas de proceso, instaladas en las ciudades de Calbuco y Puerto Montt. Estas plantas, pertenecen a capitales privados, nacionales y transnacionales -incluyendo los de origen español ${ }^{39}$. En algunos casos -empresas de mayor envergadura- comportan cierto grado de integración vertical al controlar las fases de captación de semillas, engorde y procesamiento, e incluso de distribución del producto en mercados nacionales e internacionales. De acuerdo con estimaciones de la Corporación de Fomento de la Producción, a través del programa "Mejillón de Chile"40, hay cerca de 20 plantas procesadoras (todas localizadas en la región de Los Lagos), las que compran la mayor parte de la producción, que a su vez deriva, como se dijo, de centros de cultivo controlados por las propias empresas que procesan o por grandes productores. Lo anterior contrasta con el alto porcentaje de micro y pequeñas empresas (el 89\% del total), pero que sin embargo solo producen menos del 10\% del volumen total. La misma fuente indica que el $90 \%$ de la producción se exporta fuera del país.

Más que otras pesquerías bentónicas, los mejillones constituyeron parte fundamental de la dieta de los canoreos del Pacífico suroriental ${ }^{41}$. En la década de 2000, comienzan a tener una alta demanda en el mercado español y en otros países europeos. Esta mayor demanda impulsó un proceso de modernización industrial, que dotó de mayor eficiencia a los negocios establecidos en la zona ${ }^{42} \mathrm{e}$ impulsó definitivamente el cultivo por sobre la extracción. El encadenamiento productivo del chorito, denominación tradicional del mejillón en Chile, comienza con la captación de semillas, con importante participación de cultivos artesanales. Esto ocurre porque las aguas más propicias para esa etapa del proceso se emplazan en zonas de pesca

39 Fernández y Giráldez, 2013

40 http://www.mejillondechile.cl/programa-estrategico/

41 Orquera y Piana, 2006

42 Fernández y Giráldez, 2013 
tradicional, con requerimientos de capital relativamente bajos. Luego sigue en el engorde, vinculado al segmento de las medianas y grandes empresas, para finalmente ser exportadas y distribuidas en mercados nacionales e internacionales.

En este marco, destacan dos elementos sobre la inserción de los agentes externos en el proceso de valorización. Por una parte, el posicionamiento dominante de las empresas sobre el sector artesanal, basado en figuras de trato no formal. Por otra, la mayor calidad de la semilla en aguas "controladas" por comunidades de pescadores y campesinos del bordemar. Las empresas capitalizan, por una parte, las ventajas hidrobiológicas del entorno ambiental donde se desarrolla el cultivo artesanal, y, por otra, la expertice de los pescadores y recolectores del bordemar, quiénes por generaciones han desarrollado las habilidades necesarias para aprovechar -extraer, manejar y transformar- los recursos bentónicos disponibles en el territorio. Sin embargo, dichas ventajas no son reconocidas como objeto de remuneración económica en la negociación contractual entre las partes.

En la comercialización, se advierten estrategias diferenciadas. En los mercados nacionales, encontramos la imagen del "chorito" anclada en los bucólicos y típicos paisajes de Chiloé o Reloncaví, pero sin conexión específica con las comunidades costeras tradicionales. En los mercados internacionales, se observa el posicionamiento de una marca genérica que subsume las identidades territoriales, dificultando la apropiación de las rentas inmateriales por parte de las comunidades locales. Para el mercado español, francés e italiano ${ }^{43}$, la estrategia más rentable fue re-denominarlo "mejillón", en particular Chilean mussel or Patagonian mussel ${ }^{44}$. De ese modo, el tradicional chorito podía competir con productos altamente demandados, como el mejillón de Galicia (Mytilus galloprovinvialis). Se advierte aquí cómo las empresas exportadoras desarrollan ventajas competitivas en la gestión de los valores inmateriales, pero también materiales, al conocer los deseos de los consumidores ubicados en mercados de países lejanos. Además, se pone en evidencia otra operación de sustitución simbólica, pero ahora en el ámbito de la producción misma: el chorito industrial (de cultivo) termina sustituyendo completamente al chorito artesanal.

Estos procesos de sustitución simbólica terminan generando una dinámica de invisibilización de los recursos inmateriales comunes, que impide desarrollar una estrategia colectiva de valorización de dichos activos acorde con los desafíos planteados por una economía post-industrial. Como se puede observar en el Cuadro 3, la distancia entre el precio de primera venta y el precio de exportación alcanza niveles considerables.

El carácter industrial de su explotación permite mantener una tendencia creciente de los desembarques (Figura 3), sin que el esfuerzo productivo suponga una presión excesiva sobre los ecosistemas. No obstante, los impactos en el ecosistema han sido advertidos a nivel paisajistico con la proliferenación de centros de engor-

43 Fernández y Giráldez, 2013; AMICHILE, 2012

44 Carrasco et al., 2015. 
de en determinadas zonas del mar interior (Calbuco, Cochamó y Quellón). Hay un deterioro de las condiciones hidrobiológicas que afectan a las especies nativas, especialmente en las áreas de mayor concentración de las líneas de engorde ${ }^{45}$.

Cuadro 3. Precios en primera venta y precios FOB de exportación de chorito, 2000-2016

\begin{tabular}{|c|c|c|}
\hline Año & Precios primera venta en US\$ $/ \mathrm{kg}$. & Precios FOB exportación US\$/Kg \\
\hline 2000 & 0,21 & 3,3 \\
\hline 2001 & 0,21 & 3,4 \\
\hline 2002 & 0,27 & 3,4 \\
\hline 2003 & 0,51 & 3,3 \\
\hline 2004 & 0,51 & 3,5 \\
\hline 2005 & 0,44 & 3,4 \\
\hline 2006 & 0,44 & 3,8 \\
\hline 2007 & 0,41 & 3,9 \\
\hline 2008 & 0,40 & 4,5 \\
\hline 2009 & 0,42 & 3,8 \\
\hline 2010 & 0,42 & 3,5 \\
\hline 2011 & 0,12 & 4,1 \\
\hline 2012 & Sin información & 3,9 \\
\hline 2013 & 0,30 & 4,4 \\
\hline 2014 & 0,30 & 4,6 \\
\hline 2015 & 0,28 & 4,5 \\
\hline 2016 & 0,30 & 4,1 \\
\hline
\end{tabular}

Fuente: Elaboración propia a partir de anuarios estadísticos SERNAPESCA y Banco Central de Chile.

En los dos casos, es posible constatar un severo impacto ambiental. En la acuicultura industrial (chorito), por concepto de polución del fondo marino, la columna de agua y el borde costero. En el caso de las pesquerías artesanales (erizo), por concepto de presión sobre los bancos naturales, evidenciando una sostenida disminución de la biodisponibilidad y consecuentemente de las capturas. Además, en el caso de mejillón o chorito se advierte un abandono de la práctica artesanal de capturas.

45 Carrasco et al., 2015; Fernández et al., 2018 


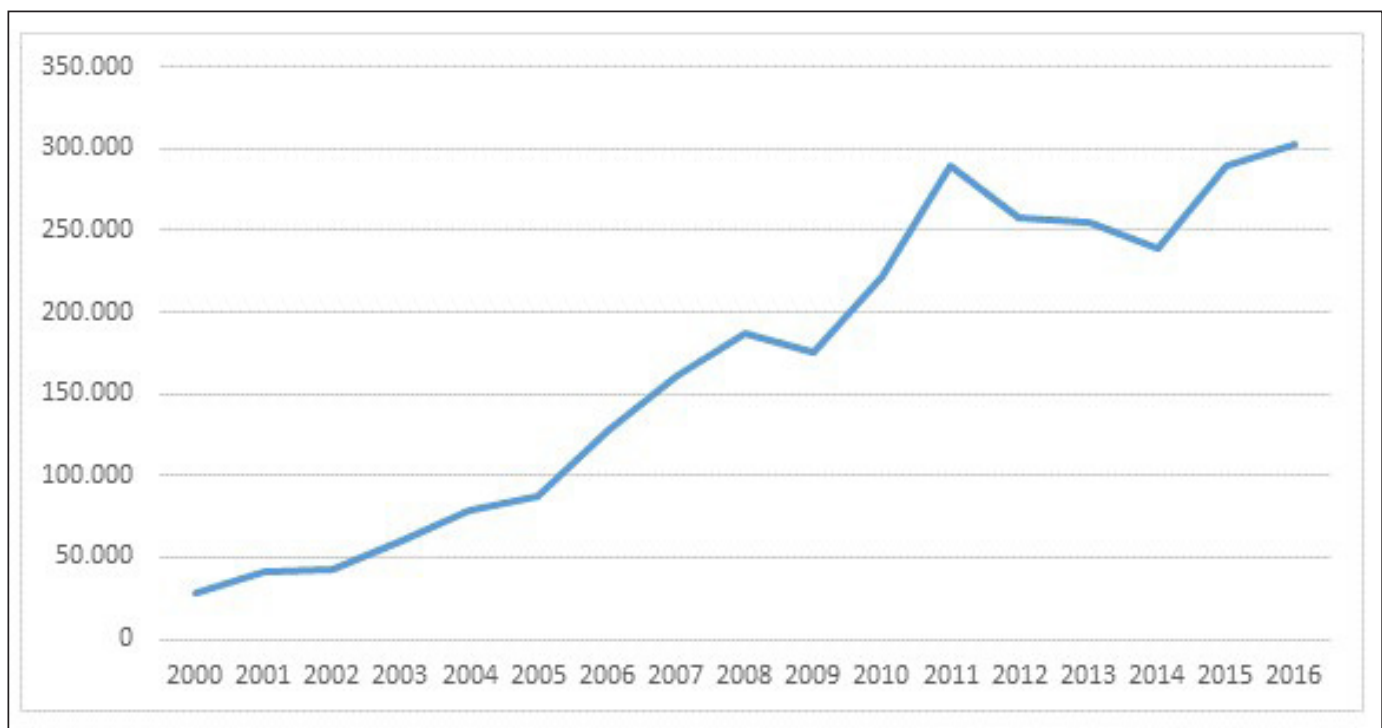

Figura 3. Desembarque de chorito en Chile (Tn), 2000-2016 Fuente: Elaboración propia a partir de anuarios estadísticos de SERNAPESCA.

\section{El lugar de los intermediarios en el proceso de obliteración de los comunes inmateriales}

Como hemos analizado, es importante subrayar los condicionantes estructurales que favorecen a las élites empresariales, relacionados con su mayor conocimiento de los mercados de consumo. Sin embargo, el trabajo etnográfico también nos aporta claves importantes sobre la contribución específica de los actores locales a este proceso. De acuerdo con los testimonios más recurrentes, los intermediarios contribuyen activamente a obstaculizar los intentos comunitarios por desarrollar una mayor capacidad de control sobre sus recursos materiales y particularmente inmateriales. Actúan bloqueando o también limitando las perspectivas del intercambio al espacio local, por ejemplo, su flujo hacia mercados de proximidad, pero también sus capacidades de control en el flujo hacia mercados nacionales distantes o incluso internacionales. Lo anterior puede verse retratado en el intento fallido de implementar en la zona de Niebla y Los Molinos (Valdivia) un proyecto denominado "Pesca en línea", el que buscaba replicar la experiencia de las subastas en España -concretamente el modelo Lonxanet en Galicia ${ }^{46}$-, pero que sin embargo no pudo imponer sus términos frente al poder de compra (y también, simbólico) de los intermediarios.

Siendo evidente la orientación exportadora de la economía del erizo y del chorito, hemos indagado en nuestros registros de campo por el destino final del producto. Las respuestas tipo más recurrentes por parte de los pescadores sostienen: "no sé, no tengo idea", "no estoy seguro", o, en menor medida, "parece que van a Japón o a China”, “a España, dicen que van". Es decir, cabe suponer que la gran mayoría de los productores locales no tiene información precisa acerca de la cadena de valor de los productos.

46 García Allut y Portela,2012. 
Al margen de si se trata de intermediarios locales o externos a las comunidades de pescadores, las representaciones locales de estos actores son predominantemente negativas. Los testimonios obtenidos son similares: “...el intermediario...te saca la plata del bolsillo. Es como un ladrón a la vista, tú sabes que el intermediario te va a robar y no tienen vergüenza para hacer lo que hacen. Son gente que trabaja pero a costilla de los pescadores"47. No obstante, los intermediarios son reconocidos como actores decisivos en la vida local, lo que pone en evidencia la incapacidad colectiva para organizar la cadena de valor. El testimonio que recogemos en Valdivia lo pone de relieve: “Uno se levanta a las 5 de la mañana, y estás llegando a las 6 de la tarde, ¡imagínate todo el día en la mar, y venir más encima a vender al restorán o a Valdivia! El cuerpo no da, no va a dar, porque tienes que descansar y al otro día ir a la pesca de nuevo, el físico no da, nunca va a dar. Entonces ese es lugar que toma el intermediario. Uno siempre va a pelear con ellos, porque siempre se ganan una buena tajada, ganan casi igual que uno, pero es necesario, a mí me facilita un montón la vida, cualquier intermediario me facilita la vida. Después uno se pone a pensar: bueno, hace más plata que yo, hace menos esfuerzo, ¿pero qué hago?, si voy a entregar [comerciar] mis cosas al otro lado pierdo de ir a pescar. Es una cosa por otra" (Grupo de conversación, Los Molinos, Valdivia, 2017).

Al cotejar las entrevistas con la data obtenida a través la encuesta de escala tipo Likert (Figura 4$)^{48}$, se refrendan y predominan las representaciones de los intermediarios como "mal necesario", "explotadores", "aprovechadores".

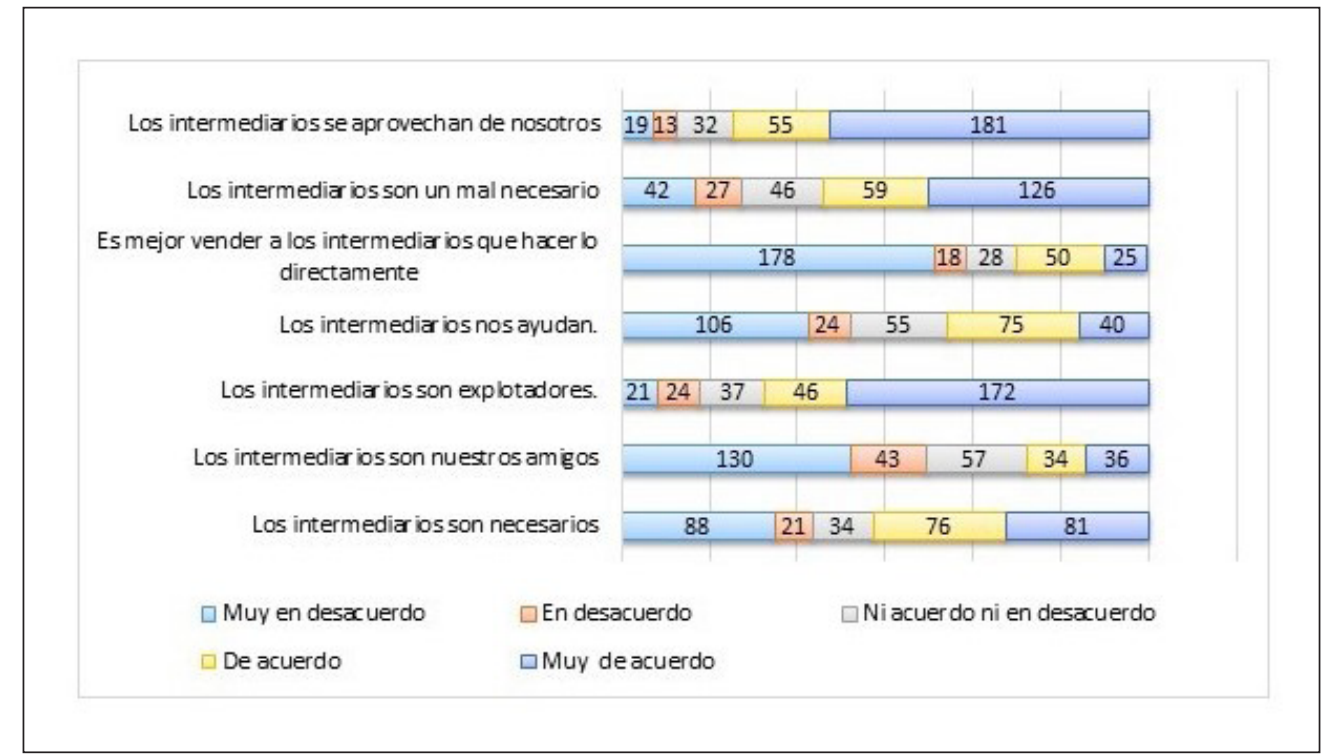

Figura 4. Grado de acuerdo sobre representaciones de intermediarios en el espacio pesquero artesanal chileno (frecuencia absoluta, $n=300$ )

Fuente: Elaboración propia.

47 Mario, Calbuco, 2017

48 En el caso de la tercera expresión de la encuesta ("es mejor vender a los intermediarios que hacerlo directamente"), cabe indicar que el " $\mathrm{n}$ " es 299 debido a un ajuste en el instrumento realizado en la fase de prueba. 
Cuando observamos este vector desde el punto de vista inverso, es decir, desde los intermediarios (o comerciantes), es posible enriquecer y matizar estas representaciones, precisamente a partir de las imágenes que estos actores construyen sobre los pescadores o sobre las comunidades de la costa sur-austral. Entre las más recurrentes cabe citar: "es que ellos tienen muy poca educación", "no son confiables", "te pueden fallar en cualquier momento". Esta última idea explica, en parte y con algunos matices, el por qué las empresas exportadoras prefieren establecer el vínculo y el trato con intermediarios y no con directamente con los pescadores. En este sentido el intermediario opera en primera instancia como un acopiador, que además realiza un procesamiento inicial de la materia prima. Por otro lado, el sistema de adelantos de insumos y dinero -transversal en la pesca artesanal, y no solo en Chile-, consagra esta asimetría estructural que deviene en la transferencia de los valores materiales e inmateriales al intermediario, quien a su vez solo las deriva al segmento exportador.

\section{Discusión y conclusiones}

En el espacio pesquero artesanal del sur chileno, una combinación de condiciones ambientales únicas y de prácticas artesanales construidas en común ha generado históricamente una producción diferenciada de productos del mar. Sin embargo, se han establecido una serie de mecanismos de apropiación y transformación de estos recursos inmateriales comunes que han puesto en peligro la sostenibilidad de la explotación de los recursos marinos y el mantenimiento de su calidad (Cuadro 4), con consecuencias negativas a largo plazo para el conjunto de actores pertenecientes a la cadena de valor (no sólo para los locales). En buena medida, esta apropiación rentista de los recursos inmateriales comunes es desarrollada por grandes grupos empresariales (Agromar, Chile Foods, Sur Mundo, etc.) que articulan estrategias de invisibilización de los recursos comunes inmateriales.

Cuadro 4. Principales variables en la gestión de los comunes inmateriales en el espacio-pesquero artesanal chileno

\begin{tabular}{lllll}
\hline Pesquería & Origen & $\begin{array}{l}\text { Obliteración de la } \\
\text { diferencia }\end{array}$ & $\begin{array}{l}\text { Valor inmaterial } \\
\text { derivado }\end{array}$ & $\begin{array}{l}\text { Agente } \\
\text { apropiador }\end{array}$ \\
\hline Erizo & $\begin{array}{l}\text { Nativo } \\
\text { artesanal }\end{array}$ & $\begin{array}{l}\text { Comercialización como } \\
\text { producto de Patagonia, } \\
\text { obliteración de su } \\
\text { localización identitaria. }\end{array}$ & $\begin{array}{l}\text { Patagonia } \\
\text { (Chiloé island) }\end{array}$ & $\begin{array}{l}\text { Empresa } \\
\text { privada }\end{array}$ \\
Chorito & $\begin{array}{l}\text { Nativo } \\
\text { industrial }\end{array}$ & $\begin{array}{l}\text { Comercialización como } \\
\text { especie sustitutiva, } \\
\text { obliteración por sustitu- } \\
\text { ción }\end{array}$ & $\begin{array}{l}\text { Mejillón gallego/ } \\
\text { Chilean Mussel/ } \\
\text { Patagonian Mussel }\end{array}$ & $\begin{array}{l}\text { Empresa } \\
\text { privada }\end{array}$ \\
\hline
\end{tabular}

Fuente: Elaboración propia.

A través de la transformación o la sustitución directa de estos recursos inmateriales comunes, su invisibilización impide a las comunidades locales desarrollar una estrategia de valorización de dichos recursos en consonancia con los retos plantea- 
dos por una economía post-industrial. Como ponemos de manifiesto en los resultados de nuestro trabajo etnográfico, esta problemática no obedece exclusivamente a una mayor capacidad competitiva de las élites empresariales a la hora de gestionar dichos recursos inmateriales (lo cual sería un reflejo de su mayor conocimiento de los deseos de los consumidores en cualquier latitud del planeta). Además, y esto es importante subrayarlo, los intermediarios, especialmente aquellos que se insertan en los eslabones de la cadena de valor más cercanos a las zonas de producción, obstaculizan activamente los intentos colectivos para desarrollar una estrategia local para gestionar el recursos inmateriales comunes. A menudo, esta labor de los intermediarios goza de la complicidad de los propios actores locales, utilizando argumentos justificativos de distinta naturaleza. Sin embargo, como apuntamos más arriba, todos los eslabones de la cadena más cercanos al territorio, incluidos los intermediarios, verán mermadas significativamente sus posiciones económicas en la medida en que la pérdida de control sobre los procesos de generación de valor de los recursos inmateriales comunes derive en una sobreexplotación de los recursos materiales y, en última instancia, en una degradación ambiental de las zonas costeras que deteriore irremediablemente la reproducción y la calidad de las especies.

A este respecto, nos planteamos cuál es el significado real de la retórica neoliberal sobre la reinvención de los territorios. Desde hace varias décadas, el neoliberalismo defiende que los territorios deben ser competitivos, emprendedores, que deben reinventarse de forma permanente haciendo uso de sus recursos, sus identidades, sus prácticas culturales, etc. Es decir, en dicha retórica las diferencias territoriales son consideradas como una mercancía más que, en un contexto de creciente competitividad global, deben buscar fórmulas imaginativas para renovarse constantemente. No obstante, lo que ponemos de manifiesto en nuestro análisis es que esta retórica encubre un proceso de obliteración de los recursos inmateriales comunes, que termina provocando un deterioro irreversible de los recursos materiales locales. Es decir, los territorios son concebidos por estas élites empresariales como auténticos espacios de depredación, que una vez esquilmados ambientalmente son sustituidos por otros todavía vírgenes. En otros trabajos de investigación desarrollados en las costas australes chilenas, se constatan procesos semejantes ${ }^{49}$.

Mientras las comunidades costeras muestran una pérdida progresiva de agencia como consecuencia de las serias deficiencias en la gestión colectiva de estos recursos inmateriales comunes, las estrategias rentistas de los grandes grupos empresariales les permiten captar una franja creciente del valor añadido, asociado al importante capital simbólico común acumulado. El impacto social y ambiental de esta pérdida de agencia de las comunidades es enorme. Como consecuencia de la necesidad de compensar la caída en los niveles de ingreso, los productores recurren a una intensificación en la explotación de los recursos naturales. En los casos donde continúan prevaleciendo las prácticas artesanales, como el erizo, esta intensificación se traduce especialmente en una caída significativa en la extracción de ambas especies. En los

49 Guerrero Valdebenito, 2018; De Matheus e Silva, Zunino y Huiliñir Curío, 2018 
casos donde imperan las prácticas industriales, como el chorito, el impacto ambiental tiene varias vertientes. Por un lado, se producen crisis sanitarias, que elevan sustancialmente la tasa de mortalidad en una determinada especie,como sucedió con la infección por virus ISA en el caso del salmón ${ }^{50}$, como consecuencia de la mayor densidad en el cultivo y la importación de especies foráneas de mayor rendimiento. Por otro lado, las formas de alimentación y de medicación asociadas a la industrialización de los cultivos marinos provocan un incremento de la contaminación de los suelos marinos y, cada vez con mayor certeza científica, problemas en la salud humana ${ }^{51}$. Además, hay que tener en cuenta las transformaciones paisajísticas en el litoral, que condicionan la vida de otras especies de la zona.

En consecuencia, se necesita ampliar el ámbito de reflexión teórica sobre la gobernanza de los bienes comunes. Como ya hemos puesto de manifiesto, en las ciencias sociales existe una tendencia mayoritaria a asociar los problemas de gestión de bienes comunes con los recursos naturales, materiales. Lo que subrayamos en este trabajo es que, en una economía post-industrial, la falta de atención que muchas comunidades muestran a la hora de gestionar los recursos inmateriales comunes genera consecuencias fatales en la explotación de los recursos naturales y en la sostenibilidad ambiental de los territorios. Por lo tanto, es necesario que todos los actores vinculados con estas actividades productivas (no sólo las comunidades, también las industrias) asuman la necesidad de dotarse de esquemas de gobernanza que les permita enfrentar estos desafíos.

Ciertamente, no se trata de una tarea fácil, si tenemos en cuenta además el entorno global tan cambiante y dinámico en el que nos movemos. Los grandes grupos empresariales que se dedican a la comercialización y exportación de estos productos pesqueros, como muchos otros, gozan de importantes ventajas competitivas a la hora de apropiarse y de transformar los recursos inmateriales comunes en una economía post-industrial. Estos grupos tienen un conocimiento de los deseos y las preferencias de los consumidores finales, que les permite vincular más eficazmente estos deseos y preferencias con los recursos inmateriales comunes que se producen a escala local. Son capaces de sintonizar a gran escala el mundo de la producción y el consumo, adaptándose rápidamente al carácter dinámico y cambiante de este último. Así, mediante mecanismos de sustitución y reformulación simbólica, son capaces de expropiar a los actores territoriales, lo que a su vez supone una destrucción progresiva de sus recursos naturales y su medio ambiente.

¿Se puede hacer algo ante esta lógica aplastante, ante esta "nueva tragedia de los comunes"? Pensamos que sí. El desempoderamiento de las comunidades locales es el resultado de su incomprensión sobre cómo se genera valor en una economía post-industrial $^{52}$. Parece claro que la situación material de los productores locales mejoraría bastante si desde las instituciones públicas se promoviese algún tipo de

50 Bustos, 2012

51 Buschmann y Fortt, 2005

52 Rullani, 2004 
cercamiento del recurso material combinado con una mayor capacidad jurídica de la comunidad para proteger las rentas asociadas a la difusión de los recursos inmateriales comunes. De esta manera, se reducirían las posibilidades de una apropiación rentista por parte de las élites locales y globales (donde el discurso hegemónico sobre la importancia de los emprendedores, termina encubriendo comportamientos "finders-keepers"). No obstante, este tipo de cercamiento material es solamente una condición necesaria. En realidad, como plantea Pasquinelli ${ }^{53}$, la condición suficiente es adoptar estrategias adecuadas de modulación entre vectores materiales e inmateriales que permitan dinamizar la gestión de los recursos inmateriales comunes, vinculando los productos locales con representaciones culturales que sean gestionadas desde la comunidad y, a la vez, sean lo suficientemente dinámicas como para vincularse exitosamente con los deseos de los consumidores en el mercado global. Dicha vinculación exitosa dependería del establecimiento de unas representaciones culturales que estimulasen la transformación dinámica de los propios deseos de los consumidores, de tal manera que el margen de reacción de las élites empresariales se redujese

\section{Bibliografía}

ARANA,P.(2005).Demografía y pesquería del erizo Loxechinus albus (Echinodermata: Echinidae) en la región sur-austral de Chile. Revista de Biología Tropical, 53, p. 367-382.

BARAHONA, N., \& MOLINET, C. (2015). Explotación de la pesquería de erizo destino fresco en la X-XI Región. http://www.subpesca.cl/institucional/602/ articles-91701_documento.pdf/Accessed Accessed 22.09.16.

BERKES, F. (2009). Evolution of co-management: role of knowledge generation, bridging organizations and social learning. Journal of environmental management, 90(5), p. 1692-1702.

BURCZAK, T. (2002). A critique of Kirzner's finders-keepers defense of profit. The Review of Austrian Economics, 15(1), p. 75-90.

BUSTOS, B. (2012). "Brote del virus ISA: crisis ambiental y capacidad de la institucionalidad ambiental para manejar el con?icto". EURE, 38 (115), p. 219245.

BUSCHMANN, A.H. y FORTT, A. (2005). Efectos ambientales de la acuicultura intensive y alternativas para un desarrollo sustentable. Ambiente y Desarrollo, $21(3)$, p. 58-64.

CANALES, M. (2006). El grupo de discusión y el grupo focal. En Canales, M. (coord.) Metodologías de la investigación social. Introducción a los oficios, p. 265-288. Santiago: LOM.

CARRASCO, A., ASTORGA, M., CISTERNA, A., FARÍAS, A., ESPINOZA, V., \& URIARTE, I. (2014). Pre-feasibility study for the installation of a Chilean Mussel Mytilus chilensis(Hupé, 1854) seed hatchery in the Lakes Region, Fisheries and Aquaculture 
Journal, 5(3).CLAUDE, M., OPORTO, J., IBÁÑEZ, C., BRIEVA, L., ESPINOSA, P. C., \& ARQUEROS, W. M. (2000). La ineficiencia de la salmonicultura en Chile: aspectos sociales, económicos y ambientales. Santiago: Terram Publicaciones.

COMAROFF, J.L., \& COMAROFF, J. (2009). Ethnicity, Inc. Chicago: University Chicago of Press.

COOPER, J. M. (1946). The Chono. En Steward (Ed.), Handbook of South American Indians. Vol. 1. Washington: Bureau of American Ethnology Bulletin.

CRUICKSHANK, J. A. (2009). A play for rurality-modernization versus local autonomy. Journal of Rural Studies 25(1), p. 98-107.

CUNNINGHAM S. \& BOSTOCK, T. (2005). Successful Fisheries Management. Issues, Case Studies and Perspectives. Amsterdam: Eburon.

DE ANGELIS, M. (2007). The beginning of history. Value struggles and global capital. Londres: Pluto Press.

DE MATHEUS E SILVA, L.F.; ZUNINO, H.M. \& HUILIÑIR CURÍO, V. (2018). El negocio de la conversación ambiental: Cómo la naturaleza se ha convertido en una nueva estrategia de acumulación capitalista en la zona andino-lacustre de Los Ríos, sur de Chile. Scripta Nova. Revista Electrónica de Geografía y Ciencias Sociales, XXII (583).

ESCOBAR, A. (2008). Territories of difference: place, movements, life, redes. Durham: Duke University Press.

FERNÁNDEZ, F., PONCE, R., VÁSQUEZ-LAVÍN, F., FIGUEROA, Y., GELCICH, S. \& DRESDNER, J. (2018). Exploring typologies of artisanal mussel seed producers in southern Chile. Ocean \& Coastal Management, 158, p. 24-31.

FERNÁNDEZ, Á., \& GIRÁLDEZ, J. (2013). Acuicultura y globalización: el caso de la industria del mejillón. Madrid: Asociación Española de Historia Económica.

FFRENCH-DAVIS, R. (2002). Chile, entre el Neoliberalismo y el Crecimiento con Equidad. Revista de Economía Política, 22(4), p. 30-47.

GARCIA ALLUT, A. G., y PORTELA, E. (2012). Nueva gobernanza de los ecosistemas costeros: una propuesta metodológica. I Congreso Iberoamericano de Gestión Integrada de Áreas Litorales. Cádiz: Red Ibermar (CYTED).

GUERRERO VALDEBENITO, R.M. (2018). Neoliberalismo y patrimonialización. Resistencia y cambio social en los procesos de patrimonialización de territorios urbanos del sur de Chile: Biobio, Araucanía y Los Ríos. Scripta Nova. Revista Electrónica de Geografía y Ciencias Sociales, XXII ( 599).

GUDEMAN, S. \& A. RIVERA. (1990). Conversations in Colombia: The Domestic Economy in Life and Text. Cambridge: Cambridge University Press.

HANLON, G. (2014). The entrepreneurial function and the capture of value: Using Kirzner to understand contemporary capitalism. Ephemera: Theory \& Politics in Organization, 14(2), p. 177-195.

HARDT, M. \& NEGRI, A. (2009). Commonwealth. Cambridge, MA: Harvard University Press.

HARVEY, D. (2012). Rebel cities: from the right to the city to the urban revolution. London 
and New York: Verso Books.

HESS, C., \& E. OSTROM (2007). Understanding Knowledge as a Commons: From Theory to Practice. Cambridge: MIT.

INSTITUTO DE FOMENTO PESQUero [FOP] (2012). Erizo. Loxechinus albus. https:// www.ifop.cl/wp-content/contenidos/uploads/recursos_amerb/Erizo_2012.pdf/ Accessed Accessed 10.03.15.

LOCKIE, S. (2001). Food, place and identity: consuming Australia's 'Beef Capital'. Journal of Sociology, 37(3), p. 239-255.

LLAGOSTERA, A. (1993). La navegación prehispánica en el norte de Chile: bioindicadores e inferencias teóricas. Chungara. Revista de Antropología Chilena, 24/25, p. 37-51.

MACÍAS VÁZQUEZ, A. \& ALONSO GONZÁLEZ, P. (2015). Managing collective symbolic capital through agro-food labelling: strategies of local communities facing neoliberalism in Spain. Journal of Rural Studies, 41, p. 142-152.

MACÍAS VÁZQUEZ, A. \& ALONSO GONZÁLEZ, P. (2016). “Knowledge Economy and the Commons: A Theoretical and Political Approach to Post-Neoliberal Common Governance", Review of Radical Political Economics, 48 (1), p. 140-157

MARAZZI, C. (2008). Capital and language: from the new economy to the war economy. Los Angeles: Semiotext(e).

MÉNDEZ, C. \& JACKSON, D. (2004). Ocupaciones humanas del Holoceno tardío en Los Vilos (IV región, Chile): Origen y características conductuales de la población local de cazadores recolectores de litoral. Chungara, Revista de Antropología Chilena, 36(2), p. 279-293.

MONTAÑÉS, M. (2010). Las Entrevistas. Cuadernos, Red CIMAS, Madrid. Recuperado el 15 de marzo de 2017, http://www.redcimas.org/wordpress/wp-content/ uploads/2012/08/m_MMontanes_LasENTREV.pdf

MORELLO, F., J. TORRES, I. MARTINEZ, K. RODRIGUEZ, M. ARROYO-KALIN, C. FRENCH, V. SIERPE \& M. SAN ROMÁN (2012). Arqueología de la Punta Santa Ana: reconstrucción de secuencias de ocupación de cazadores-recolectores marinos del estrecho de Magallanes, Patagonia austral, Chile. Magallania, 40(2), p. 129-149.

NAHUELHUAL, L., G., SAAVEDRA, G., BLANCO, E., WESSELINK, G., CAMPOS, \& X. VERGARA. (2018). On super fishers and black capture: Images of illegal fishing in artisanal fisheries of southern Chile. Marine Policy, 95, p. 36-45.

ORQUERA L.\& E.PIANA (2006). El poblamiento inicial del área litoral sudamericana sudoccidental. Magallania 34 ( 2), p. 21-36.

OSTROM, E. (1990). Governing the commons: The evolution of institutions for collective action. Cambridge: Cambridge University Press.

PASQUINELLI, M. (2008). Animal spirits: a bestiary of the commons. Rotterdam: NAi. PEÑA-TORRES, J. (1997). The Political Economy of Fishing Regulation: The Case ofChile. Marine Resource Economics 253, p. 14-15.

PRATT, J. (2007). Food values. The local and the authentic. Critique of Anthropology, 
27(3), p. 285-300.

QUIROZ, D. \& SÁNCHEZ, M. (2004). Poblamientos iniciales en la costa septentrional de la Araucanía (6500-2000 a. p.). Chungará. Revista de Antropología Chilena, 36 (supl.), p. 289-302.

RAY, C. (1998). Culture, intellectual property and territorial rural development. Sociologia Ruralis, 38 (1), p. 3-20.

RESTREPO, E. (2011). Modernidad y Diferencia. Tabula Rasa, 14, p. 125-154.

REYES, O., MÉNDEZ, C., SAN ROMÁN, CÁRDENAS, P., VELÁSQUEZ, H., TREJO, V., MORELLO, F., \& STERN, C. (2007). Seno gala 1:Nuevos resultados en la arqueología de los canales septentrionales ( $44^{\circ}$ s, región de Aisén, chile). Magallania, 35(2), p. 105-119.

RULLANI, E. (2004). Economia della conoscenza: creatività e valore nel capitalismo delle reti. Roma: Carocci.SERRES, M. (2014). Le parasite. París: Fayard/Pluriel.

SERVICIO NACIONAL DE PESCA Y ACUICULTURA [SERNAPESCA]. (2000-2016). Anuario estadístico de pesca. Valparaíso: Departamento de Pesca Artesanal.

SERVICIO NACIONAL DE PESCA Y ACUICULTURA [SERNAPESCA]. (2015). RPA - Pescadores y Embarcaciones, Registro Pesquero Artesanal. Valparaíso: Departamento de Pesca Artesanal.

SIERRA CABALLERO, F. (2019). Teoría del valor, comunicación y territorio. Madrid: Siglo XXI.

SKEWES, J. C., ÁLVAREZ, R., \& NAVARRO, M.(2012). Usos consuetudinarios, conflictos actuales y conservación en el borde costero de Chiloé insular. Magallania, 40(1), p. 109-125.

THRIFT, N. (2005). Knowing Capitalism. Londres: Sage.

VAN LAERHOVEN, F., \& OSTROM, E. (2007). Traditions and Trends in the Study of the Commons. International Journal of the Commons, $1(1)$, p. 3-28.

VERCELLONE, C. (2008). The Art of Rent. London: Queen Mary University.

ZEPEDA, L., REZNICKOVA, A., RUSSELL, W.S., \& HETTEMBACH, D. (2014). A case study of the symbolic value of Community Supported Agriculture membership. Journal of Food Distribution Research, 45(2), p. 195-212.

(C) Copyright: Alfredo Macías Vázquez y Gonzalo Saavedra Gallo, 2020

(C) Copyright: Scripta Nova, 2020.

Ficha bibliográfica:

MACÍAS VÁZQUEZ, Alfredo; SAAVEDRA GALLO, Gonzalo. Diferencias territoriales, sostenibilidad y comunes inmateriales en las costas australes chilenas. Scripta Nova. Revista Electrónica de Geografía y Ciencias Sociales. Barcelona: Universidad de Barcelona, 1 de Agosto de 2020, vol. XXIV, $\mathrm{n}^{\circ}$ 643. [ISSN: 1138-9788] 